\title{
Article
}

\section{The Kenya Case of Multivariate Causality of Carbon Dioxide Emissions}

\author{
Samuel Asumadu-Sarkodie * and Phebe Asantewaa Owusu \\ Sustainable Environment and Energy Systems \\ Northern Cyprus Campus, Middle East Technical University, \\ Kalkanli, Guzelyurt, TRNC 99738/Mersin 10, Turkey; \\ phebe.owusu@metu.edu.tr \\ * Correspondence: samuelsarkodie@yahoo.com
}

\begin{abstract}
In this study, an attempt was made to investigate the Kenya case of multivariate causality of carbon dioxide emissions by employing a time series data spanning from 1961-2011 using the ARDL method of cointegration analysis. The long-run elasticities show that, a $1 \%$ increase in financial development increases carbon dioxide emissions by $0.28 \%$, a $1 \%$ increase in GDP per capita increases carbon dioxide emissions by $1.32 \%$ and a $1 \%$ increase in urbanization decreases carbon dioxide emissions by $1.14 \%$. There was a unidirectional causality running from financial development, food production index, GDP per capita, industrialization and urbanization to carbon dioxide emissions. The innovation accounting shows that $20 \%$ of future shocks in carbon dioxide emissions are due to fluctuations in financial development, $9 \%$ of future shocks in financial development are due to fluctuations urbanization and $22 \%$ of future shocks in food production index are due to fluctuations in carbon dioxide emissions.
\end{abstract}

Keywords: Granger-causality; carbon dioxide emissions; ARDL; Kenya; variance decomposition; climate change

JEL Classification: Q53; O44; Q10; Q54 


\section{INTRODUCTION}

Climate change has taken the centre stage in the developmental agenda in developed and developing countries [1]. Global effort has been made through the establishment of the sustainable development goals to promote renewable and clean energy technologies, sustainable agriculture and food security, and mitigate climate change and its impact. There is a close relationship between carbon dioxide emissions, industrialization, urbanization, financial development, economic growth and human well-being [2,3,4,5]. This is because industrialization, urbanization, financial development, economic growth and carbon dioxide emissions have significant bearing on human development indicators such as incomes, wage employment, skill formation, improved livelihoods (air quality, clean environment, nutrition and health care), gender parity, and entrepreneurship. Significantly, industrial and technological advancement have played a role in food production, processing, storage, nutrition, food security and agricultural tools and techniques [6,7].

The human development index measures the geometric mean of life expectancy, educational attainment and standard of living which are critical for climate change mitigation vulnerability index [6]. The 2015 version of the human development report by the United Nations Development Programme indicates that Kenya has a low human development index of 0.548/1 ranking below Zambia $(0.586 / 1)$ but higher than the other East African countries such as; Burundi (0.4/1), Djibouti (0.47/1), Eritrea (0.391/1), Ethiopia (0.442/1), Madagascar (0.51/1), Malawi (0.445/1), Mozambique (0.416/1), Rwanda (0.483/1), South Sudan (0.467/1), Tanzania (0.521/1), Uganda (0.483/1) and Zimbabwe (0.506/1). The report further indicates that Kenya has a gross national income (GNI) per capita of US\$2,761.6, 48.2\% of the population are in multidimensional poverty, 0.3 tonnes of carbon dioxide emission per capita and a population of 45.5 million [8]. 
As a result of the high levels of multidimensional poverty, the Government of Kenya is working closely to improving the welfare of Kenyans through industrialization. There has been significant improvement in Kenya's industry policies since mid-1980s leading to its vast contribution to the country's GDP, source of employment opportunities and increasing the industrial output through manufacturing activities [6]. Notwithstanding, there are challenges associated with industrialization such as; rapid urbanization and poor environmental and health quality as a result of industrial carbon dioxide emissions [9].

According to UNDP [8], changes in climatic patters as a result of global carbon dioxide emissions are now creating harmful impacts on the Kenyan environment, society and economy. As a result of uncertainties about weather patterns, economic sectors like tourism and agriculture are accruing a significant economic loss. According to IMF [10], "Kenya remains vulnerable to financial shocks that could have a significant adverse impact on the economy". It is projected that Kenya will require about US\$ 1-2 billion yearly by 2030 to address the current and future climate change effects [11].

Against the backdrop, it is worthwhile to examine the multivariate causality of carbon dioxide emissions in Kenya using a time series data spanning from 1961-2011. To the best of our knowledge, the scope of the study is the first time in Kenya which will contribute to existing literature from the Kenya case and further increase the global debate on climate change from the Kenya perspective. Since carbon dioxide emissions, energy consumption/production and GDP have been proven to be collinear in many studies from different countries $[12,13]$. The current study eliminates energy consumption/production and rather examines the equilibrium relationship between carbon dioxide emissions, food production index, financial development, economic growth, industrialization and urbanization using the ARDL method of cointegration analysis. The study further estimates the Granger-causality and the variance decomposition based on VAR. 
The remainder of the study consist of "Literature review", "Methodology", "Results and Discussion" and "Conclusion and Policy recommendations".

\section{LITERATURE REVIEW}

Within the last decades, the relationship between environmental pollution, energy consumption and macroeconomic variables (financial development and economic growth) have received considerable attention in scientific literature.

The first set of studies including Cerdeira Bento and Moutinho [14], SekerErtugrul and Cetin [15], Apergis and Ozturk [16], Baek [17], NarayanSaboori and Soleymani [18], Acaravci and Ozturk [19], OsabuohienEfobi and Gitau [20], Tutulmaz [21], TiwariShahbaz and Adnan Hye [22], Ben AbdallahBelloumi and De Wolf [23], ShahbazLean and Shabbir [24], Balaguer and Cantavella [25], Babu and Datta [26], Asici and Acar [27], Ben JebliBen Youssef and Ozturk [28], BilgiliKocak and Bulut [29], Al-MulaliSolarin and Ozturk [30], Fujii and Managi [31], KangZhao and Yang [32], Asumadu-Sarkodie and Owusu [33], Hao and Liu [34], Javid and Sharif [35], OzturkAl-Mulali and Saboori [36], Narayan and Narayan [37], among others have investigated the validity of the Environmental Kuznets Curve hypothesis which suggests that environmental degradation/pollution decreases overtime as a country's GDP per capita increases. Cerdeira Bento and Moutinho [14], SekerErtugrul and Cetin [15], Apergis and Ozturk [16], ShahbazLean and Shabbir [24], Charfeddine and Khediri [38], Balaguer and Cantavella [25], Al-MulaliSolarin and Ozturk [30], BilgiliKocak and Bulut [29], Hao and Liu [34], Javid and Sharif [35] and among others support the validity of the Environmental Kuznets Curve hypothesis while Al-TorkistaniSalisu and Maimany [39], LiuYan and Zhou [40], among others reject the validity of the Environmental Kuznets Curve hypothesis.

The second set of studies including Acaravci and Ozturk [19],Ohler and Fetters [41],Azhar KhanZahir KhanZaman et al. [42],CaraianiLungu and Dascălu [43],Fuinhas and Marques [44], 
Apergis and Ozturk [16],Chang [45],ChenKuo and Chen [46], Azhar KhanZahir KhanZaman et al. [42],Ozturk and Acaravci [47],Sadorsky [48], Asumadu-Sarkodie and Owusu [49], Pao and Tsai [50], HatzigeorgiouPolatidis and Haralambopoulos [51], Asumadu-Sarkodie and Owusu [52], Soytas and Sari [53], HuangHwang and Yang [54], Lozano and Gutiérrez [55], GulZouHassan et al. [56], Jammazi and Aloui [57], QureshiRasli and Zaman [58], AsumaduSarkodie and Owusu [59], MohiuddinAsumadu-Sarkodie and Obaidullah [60], examines the relationship between environmental pollution, energy consumption and economic growth. HuangHwang and Yang [54] found no relationship between energy consumption and GDP. Soytas and Sari [53] found that carbon dioxide emissions Granger cause energy consumption while Zhang and Cheng [61] found no evidence of causality from carbon dioxide emissions or energy consumption to economic growth. GulZouHassan et al. [56] found evidence of a unidirectional causality running from energy-consumption to carbon dioxide emissions. Jammazi and Aloui [57] found a bidirectional causality between energy consumption and economic growth, and a unidirectional causality between energy consumption and carbon dioxide emissions.

Finally, the third set of studies; Al-MulaliSolarin and Ozturk [30], SekerErtugrul and Cetin [15], Javid and Sharif [35],ShahbazJamBibi et al. [62], KangZhao and Yang [32], OzturkAlMulali and Saboori [36], Asumadu-Sarkodie and Owusu [63, 64, 65, 66], Saidi and Hammami [67], AhmedShahbaz and Kyophilavong [68], Asumadu-Sarkodie and Owusu [63] include other macroeconomic variables such as industrialization, urbanization, financial development, trade openness, etc. to the already existing variables in literature such as; carbon dioxide emissions, population, energy consumption and economic growth. A majority of the studies shows evidence of a long-run and short-run equilibrium relationship and a causal effect between environmental pollution and macroeconomic variables [52,63,64,65,66]. 
Almost a majority of literature in the scope of the study are investigated in European countries $[19,41,42,43,44]$, Asian countries [16,45,46,69] and the Middle East countries $[42,47,48]$ with a handful of literature in Africa [7,12,13,20,30,70].

Nevertheless, the scope of the study is sporadic and limited in Kenya. To the best of our knowledge, only Al-MulaliSolarin and Ozturk [30] have examined the validity of the Environmental Kuznets Curve hypothesis in Kenya with a time series data spanning from 19802012 using the ARDL method of cointegration analysis. Their study does not support the validity of the EKC in Kenya. Unlike their study, the current study examines the relationship between carbon dioxide emissions, food production index, GDP per capita, financial development, industrialization and urbanization. In addition, the direction of causality and innovation accounting using Cholesky's technique is employed in the Kenya case which were absent in previous study [30]. The study contributes to existing literature by expanding the period of the time series data from 1961-2011 compared to previous 1980-2012, in order to provide formidable statistical evidence. Moreover, the study increases the global debate on climate change and its impact from the Kenya context and serve as a policy document for future national planning and strategies on climate change mitigation.

\section{METHODOLOGY}

\subsection{Data}

The study investigates the Kenya case of multivariate causality of carbon dioxide emissions by employing a time series data from the World Bank [71] at a period spanning from 1961-2011 using the ARDL method of cointegration analysis. Six study variables are used in the study which include: $\mathrm{CO}_{2}$ - Carbon dioxide emissions (kt), GDPPC - Gross Domestic Product per capita (current LCU), IND-Industry, value added (current LCU), FPI-Food production index (2004-2006 = 100), FD-Money and quasi money (M2) (current LCU), URB-Urban population. 
The World Bank [71] defines Money and quasi money as "the sum of currency outside banks, demand deposits other than those of the central government, and the time, savings, and foreign currency deposits of resident sectors other than the central government", it is therefore used as a proxy for financial development (FD). Moreover, the World Bank [71] defines Industry value added as "the value added to mining, manufacturing, construction, electricity, water and gas", it is therefore used as a proxy for industrialization (INV) [71].

\subsection{Descriptive Analysis}

The study presents the descriptive statistical analysis of the time series variables from 51 observations as showed in Table 1. Information from Table 1 shows that all the variables exhibit a long-right-tail (positive skewness) with INV having the higher skewness. While FD, GDPPC, and INV exhibit leptokurtic distribution, $\mathrm{CO}_{2}$, FPI and URB exhibit a platkurtic distribution.

The correlation analysis shows that all the independent variables have a positive monotonic relationship with $\mathrm{CO}_{2}$. Jarque-Bera test statistic suggests that FD, GDPPC and INV are not normally distributed based on 5\% significance level. Therefore, a logarithmic transformation is applied to the variables in order to provide a more stable data variance for the subsequent analysis. At this juncture, let $\mathrm{LCO}_{2}$, LFD, LFPI, LGDPPC, LINV and LURB represent the logarithmic transformation of $\mathrm{CO}_{2}, \mathrm{FD}, \mathrm{FPI}, \mathrm{GDPPC}$, INV and URB.

Figure 1 shows the trend of the study variables. Figure 1 shows that carbon dioxide emissions, financial development, food production index, GDP per capita, industrialization, and urbanization increase periodically which suggest the existent of a strong relationship among them. However, the trend of carbon dioxide emissions decreased over the period 2000-2003 due to a decline of oil imports as a result of Kenya's energy efficiency and conservation policy $[2]$. 
Table 1. Descriptive Statistical Analysis

\begin{tabular}{|c|c|c|c|c|c|c|}
\hline Statistic & $\mathrm{CO}_{2}$ & FD & FPI & GDPPC & INV & URB \\
\hline Mean & 6110.784 & $2.16 \mathrm{E}+11$ & 59.12549 & 17282.69 & $1.01 \mathrm{E}+11$ & 3917490 \\
\hline Median & 5170 & $3.57 \mathrm{E}+10$ & 57 & 5760 & $1.90 \mathrm{E}+10$ & 3300000 \\
\hline Maximum & 13600 & $1.52 \mathrm{E}+12$ & 124 & 90000 & $7.04 \mathrm{E}+11$ & 9930000 \\
\hline Minimum & 2400 & $2.22 \mathrm{E}+08$ & 23.9 & 677 & $9.25 \mathrm{E}+08$ & 633000 \\
\hline Std. Dev. & 2920.942 & $3.49 \mathrm{E}+11$ & 28.45324 & 22788.33 & $1.68 \mathrm{E}+11$ & 2705770 \\
\hline Skewness & 0.7509 & 2.0892 & 0.6805 & 1.6062 & 2.1058 & 0.6118 \\
\hline Kurtosis & 2.6607 & 6.9793 & 2.5152 & 4.7652 & 6.6566 & 2.2499 \\
\hline Jarque-Bera & 5.0370 & 70.7493 & 4.4355 & 28.5499 & 66.1043 & 4.3771 \\
\hline Probability & 0.0806 & 0.0000 & 0.1089 & 0.0000 & 0.0000 & 0.1121 \\
\hline \multicolumn{7}{|l|}{ Correlation } \\
\hline $\mathrm{CO}_{2}$ & 1 & & & & & \\
\hline FD & 0.8670 & 1 & & & & \\
\hline FPI & 0.9018 & 0.8870 & 1 & & & \\
\hline GDPPC & 0.9096 & 0.9889 & 0.9288 & 1 & & \\
\hline INV & 0.8531 & 0.9947 & 0.8818 & 0.9857 & 1 & \\
\hline URB & 0.9311 & 0.8914 & 0.9896 & 0.9377 & 0.8788 & 1 \\
\hline
\end{tabular}



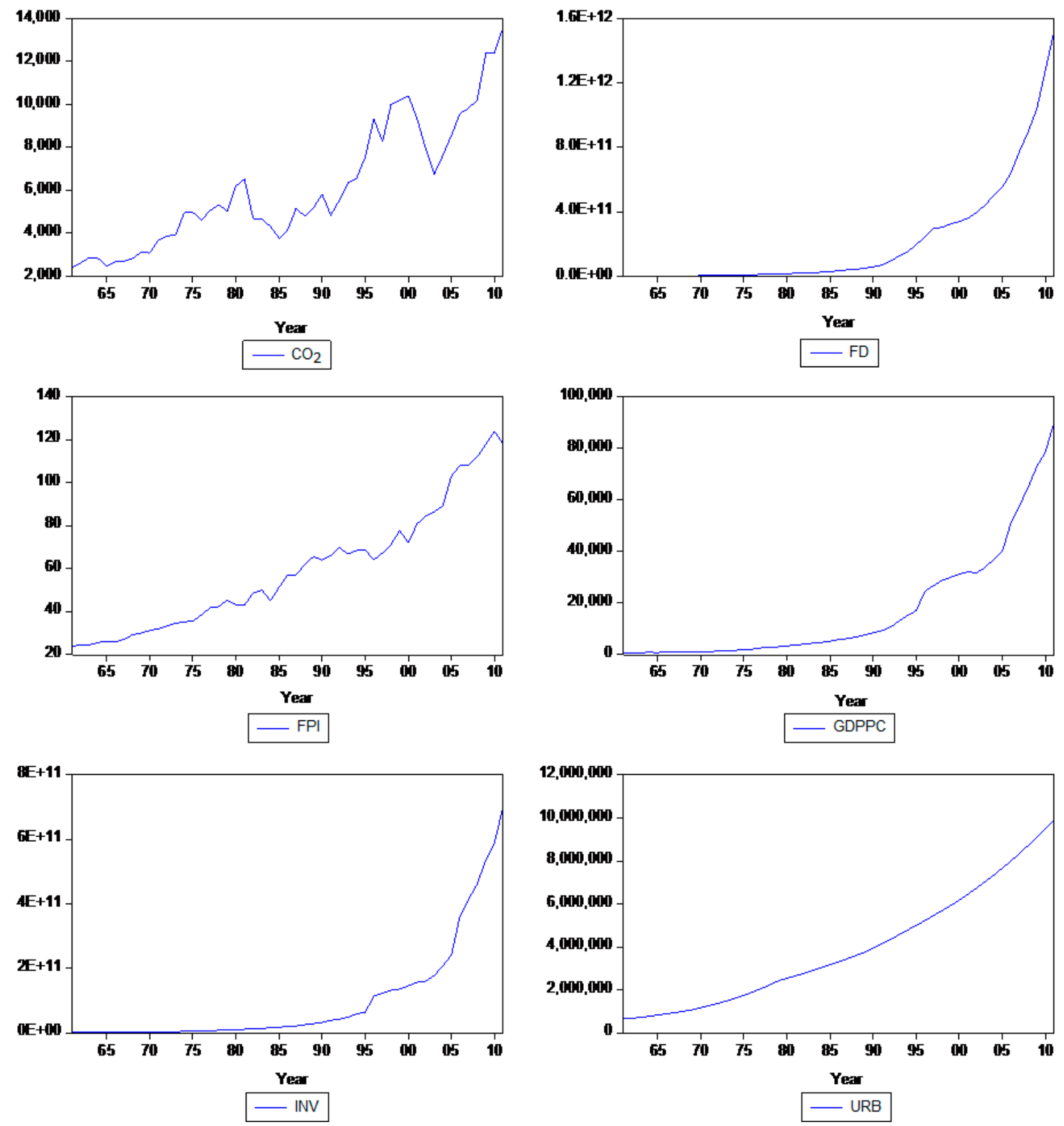

Figure 1. Trend of Variables

\subsection{Stationarity Test}

The empirical analysis begins with testing for the stationarity properties of the variables. The study employs the Kwiatkowski-Phillips-Schmidt-Shin (KPSS) and Vogelsang's breakpoint tests in order to have a robust result. KPSS test results in Table 2 shows some different specifications, however the null hypothesis of stationarity is rejected at level in all the variables but cannot be rejected at first difference based on 5\% significance level. Since KPSS fails to 
test the stationarity in the presence of structural breaks, the study estimates the order of integration with Vogelsang's breakpoint unit root test by considering the presence of innovational outliers. Information from Table 2 shows that, the null hypothesis of nonstationarity cannot be rejected at level, but rejected at first difference based on 5\% significance level. Meaning that KPSS and Vogelsang's breakpoint tests suggest that the variables are integrated of $\mathrm{I}(1)$. 
Table 2. Kwiatkowski-Phillips-Schmidt-Shin and Breakpoint Tests

\begin{tabular}{|c|c|c|c|c|c|c|c|c|c|c|c|c|}
\hline \multirow{2}{*}{$\begin{array}{l}\text { Test } \\
\text { KPSS Level }\end{array}$} & \multicolumn{2}{|c|}{$\mathrm{LCO}_{2}$} & \multicolumn{2}{|c|}{ LFD } & \multicolumn{2}{|c|}{ LFPI } & \multicolumn{2}{|c|}{ LGDPPC } & \multicolumn{2}{|c|}{ LINV } & \multicolumn{2}{|c|}{ LURB } \\
\hline & Test Stats & Prob & Test Stats & Prob & Test Stats & Prob & Test Stats & Prob & Test Stats & Prob & Test Stats & Prob \\
\hline Intercept & 0.8913 & $0.4630^{*}$ & 0.9525 & $0.4630^{*}$ & 0.9484 & $0.4630^{*}$ & 0.9524 & $0.4630^{*}$ & 0.9561 & $0.4630^{*}$ & 0.9456 & $0.4630^{*}$ \\
\hline Trend and & 0.0591 & 0.1460 & 0.1508 & $0.1460^{*}$ & 0.0747 & 0.1460 & 0.1116 & 0.1460 & 0.0983 & 0.1460 & 0.2331 & $0.1460^{*}$ \\
\hline \multicolumn{13}{|l|}{ Intercept } \\
\hline \multicolumn{13}{|c|}{ KPSS 1st Diff } \\
\hline Intercept & 0.0512 & 0.4630 & 0.2410 & 0.4630 & 0.0278 & 0.4630 & 0.1925 & 0.4630 & 0.1887 & 0.4630 & 0.3470 & 0.4630 \\
\hline Trend and & 0.0492 & 0.1460 & 0.0880 & 0.1460 & 0.0277 & 0.1460 & 0.0785 & 0.1460 & 0.0569 & 0.1460 & 0.0945 & 0.1460 \\
\hline \multicolumn{13}{|l|}{ Intercept } \\
\hline \multicolumn{13}{|c|}{ Break test Level } \\
\hline Intercept & -2.2343 & 0.9580 & -2.2840 & 0.9493 & -1.5761 & $>0.99$ & -0.2615 & $>0.99$ & 0.0807 & $>0.99$ & -2.9021 & 0.7379 \\
\hline Trend and & -4.7817 & 0.0622 & -3.1726 & 0.9312 & -4.5622 & 0.1126 & -3.0540 & 0.6751 & -3.6665 & 0.3183 & -2.9604 & 0.9228 \\
\hline \multicolumn{13}{|l|}{ Intercept } \\
\hline \multicolumn{13}{|c|}{ Break test 1st Diff } \\
\hline Intercept & -7.7485 & $<0.01^{*}$ & -6.8732 & $<0.01^{*}$ & -8.4967 & $<0.01^{*}$ & -6.7204 & $<0.01^{*}$ & -7.5567 & $<0.01^{*}$ & -7.9637 & $<0.01^{*}$ \\
\hline Trend and & -7.6755 & $<0.01^{*}$ & -6.9269 & $<0.01^{*}$ & -8.3607 & $<0.01^{*}$ & -7.6873 & $<0.01^{*}$ & -9.3659 & $<0.01^{*}$ & -7.9070 & $<0.01^{*}$ \\
\hline Intercept & & & & & & & & & & & & \\
\hline
\end{tabular}




\subsection{Model Estimation}

The relationship between carbon dioxide emissions, food production index, financial development, GDP per capita, industrialization and urbanization in Kenya is expressed as a linear function showed in equation (1):

$L C O 2_{t}=f\left(L F D_{t}, L F P I_{t}, L G D P P C_{t}, L I N V_{t}, L U R B_{t}\right)$

The empirical specifications for the selected $\operatorname{ARDL}(1,1,1,1,0,2)$ model is quantified as:

$$
\begin{aligned}
& L C O_{2}=\beta_{1} L C O_{2 t-1}+\beta_{2} L F D_{t}+\beta_{3} L F D_{t-1}+\beta_{4} L F P I_{t}+\beta_{5} L F P I_{t-1}+\beta_{6} L G D P P C_{t}+ \\
& \beta_{7} L G D P P C_{t-1}+\beta_{8} L I N V_{t}+\beta_{9} L U R B_{t}+\beta_{10} L U R B_{t-1}+\beta_{11} L U R B_{t-2}+\beta_{12}
\end{aligned}
$$

where $L_{C O} \mathrm{2}_{t}$ is the dependent variable while $L F D_{t}, L F P I_{t}, L G D P P C_{t}, L I N V_{t}$ and $L U R B_{t}$ are the explanatory variables in year $t, t-1$ and $t-2$ represents lag 1 and 2 and $\beta$ 's are the elasticities to be estimated. The substituted coefficients from the estimated equation are; $\beta_{1}=$ $0.63(0.00), \beta_{2}=-0.04(0.25), \beta_{3}=0.15(0.00), \beta_{4}=-0.20(0.36), \beta_{5}=0.63(0.00)$, $\beta_{6}=1.05(0.00), \quad \beta_{7}=-0.56(0.00), \quad \beta_{8}=-0.34(0.03), \quad \beta_{9}=-5.70(0.02), \quad \beta_{10}=$ $13.89(0.00), \beta_{11}=-8.61(0.00)$ and $\beta_{12}=8.82(0.00)$. The estimated coefficients are all significant at $5 \%$ level with the exception of $L F D_{t}$ and $L F P I_{t}$.

The study employs the ARDL method of cointegration to estimate the long-run and short-run equilibrium relationship between $\mathrm{LCO}_{2}$, LFD, LFPI, LGDPPC, LINV and LURB. Following the work of Asumadu-Sarkodie and Owusu [7],Asumadu-Sarkodie and Owusu [12] and AlMulaliSolarin and Ozturk [30], the ARDL co-integrating equation is expressed as:

$$
\begin{aligned}
& \Delta L C O_{2}=\alpha_{0}+\delta_{1} L C O 2_{t-1}+\delta_{2} L F D_{t-1}+\delta_{3} L F P I_{t-1}+\delta_{4} L G D P P C_{t-1}+\delta_{5} L I N V_{t-1}+ \\
& \delta_{6} L U R B_{t-1}+\sum_{i=1}^{k} \beta_{1} \Delta L C O_{2} t-i \\
& \sum_{i=0}^{k} \beta_{4} \Delta L G D P P C_{t-i}+\sum_{i=0}^{k} \beta_{2} \Delta L F D_{t-i}+\sum_{i=0}^{k} \beta_{3} \Delta L F P I_{t-i}+
\end{aligned}
$$


where $\alpha$ is the intercept, $k$ is the lag order, $\varepsilon_{t}$ is the error term and $\Delta$ is the first difference operator. The application of ARDL cointegration among variables can be estimated at either $\mathrm{I}(0)$ or I(1) without pre-specification of variables which are either $\mathrm{I}(0)$ or $\mathrm{I}(1)$. Moreover, ARDL has desirable small sample properties and provide unbiased long-run estimation, even when some endogenous variables behave as regressors. The initial step of ARDL cointegration is the bounds testing procedure which is based on the F-test. The Null hypothesis of no cointegration between $\mathrm{LCO}_{2}$, LFD, LFPI, LGDPPC, LINV and LURB is $H_{0}: \delta_{1}=\delta_{2}=\delta_{3}=$ $\delta_{4}=\delta_{5}=\delta_{6}=0$ Against the Alternative hypothesis $H_{1}: \delta_{1} \neq \delta_{2} \neq \delta_{3} \neq \delta_{4} \neq \delta_{5} \neq \delta_{6} \neq 0$. According to PesaranShin and Smith [72], the calculated F-statistic is compared with the critical values of the lower and upper bounds respectively. If the calculated F-statistic goes above the upper bound, the null hypothesis of no cointegration between is rejected. However, if the F-statistic is smaller than the critical value of the lower bound, the null hypothesis of no cointegration cannot be rejected. In addition, if the F-statistic lies between the critical values of the lower and the upper bounds, the null hypothesis of no cointegration become inconclusive, which requires either the estimation of Johansen's test of cointegration [73] or through testing the constancy of the cointegration space using CUSUM and CUSUM of squares of residuals [74].

Unlike Johannsen's method of cointegration approach which employs a set of cointegration equations to analyse the long-run equilibrium relationship between variables, the ARDL method of cointegration by PesaranShin and Smith [72] adopts only one equation as expressed in equation (4):

Cointeq $=L_{C O}-(0.2799 * L F D+1.1445 * L F P I+1.3193 * L G D P P C-0.9094 *$

$L I N V-1.1365 * L U R B+23.8058)$ 
The joint short-run effect is estimated using the Wald test of linear restrictions to the coefficients of LFD, LFPI, LGDPPC, LINV and LURB in equation (2). From equation (2), we derive that $\beta_{2}=\beta_{3}=0, \beta_{4}=\beta_{5}=0, \beta_{6}=\beta_{7}=0, \beta_{8}=0$ and $\beta_{9}=\beta_{10}=\beta_{11}=0$.

\section{RESULTS AND DISCUSSION}

This section presents the results and a discussion of the empirical analysis.

\subsection{ARDL Co-integration}

Having determined the integration of variables at I(1), the study selects an optimal model using the Schwarz Criteria. As stated in equation (2), the selected model using the Schwarz Criteria is $\operatorname{ARDL}(1,1,1,1,0,2)$ as shown in Figure 2. Using the optimal model, the ARDL bounds testing is estimated as showed in Table 3. Table 3 shows that the F-statistic lies above the critical values of the upper bound at 10, 5 and $2.5 \%$ significance level, therefore the null hypothesis of no long-run relationship is rejected at 5\% significance level. Table 3 further presents the error correction, long-run elasticities and short-run equilibrium relationship. Table 3 shows that the speed of adjustment [ECT $(-1)=-0.37]$ is negative and significant at $5 \%$ level, meaning that a long-run equilibrium relationship exist running from LFD, LFPI, LGDPPC, LINV and LURB to $\mathrm{LCO}_{2}$. The joint test of linear restrictions of the coefficient in the shortrun estimates shows that LFD, LFPI, LGDPPC, LINV and LURB affect $\mathrm{LCO}_{2}$ in a short-run.

The evidence from the long-run elasticities in Table 3 has policy implications for Kenya. Table 3 shows that, a $1 \%$ increase in LFD increases $\mathrm{LCO}_{2}$ by $0.28 \%$, a $1 \%$ increase in LGDPPC increases $\mathrm{LCO}_{2}$ by $1.32 \%$ and a $1 \%$ increase in LURB decreases $\mathrm{LCO}_{2}$ by $1.14 \%$. 


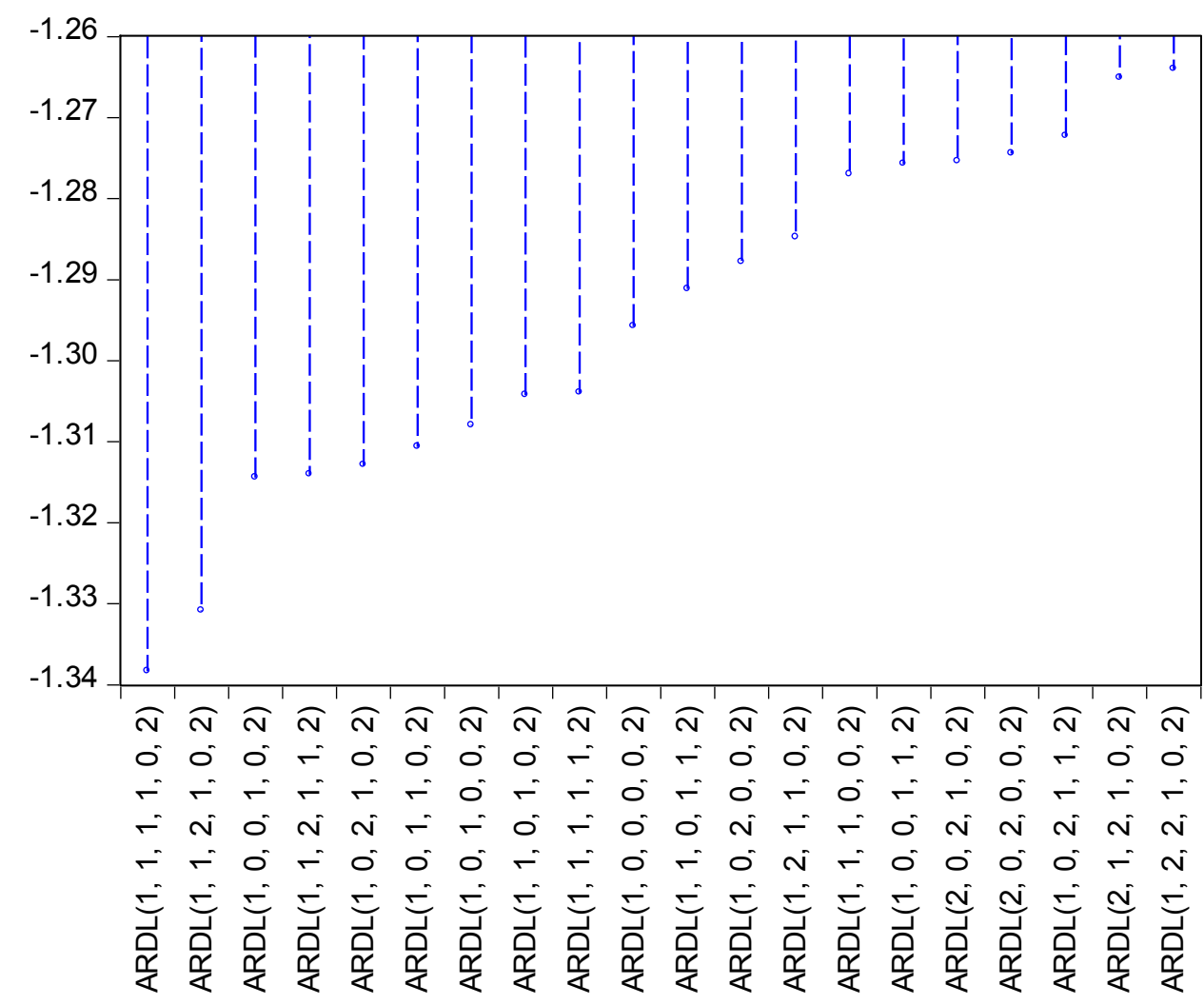

Figure 2. Schwarz Criteria for Model Selection

Table 3. ARDL Bounds Test, Error Correction, Long-Run and Short-Run Relationship

\begin{tabular}{|c|c|c|c|c|}
\hline \multicolumn{5}{|c|}{ 5. Bounds Test } \\
\hline Test Statistic & \multicolumn{3}{|c|}{ Value } & $\mathrm{k}$ \\
\hline F-statistic & \multicolumn{3}{|c|}{3.77} & 5 \\
\hline \multicolumn{5}{|c|}{ Critical Value Bounds } \\
\hline Significance & \multicolumn{3}{|c|}{ I0 Bound } & I1 Bound \\
\hline $10 \%$ & \multicolumn{3}{|c|}{2.08} & 3.00 \\
\hline $5 \%$ & \multicolumn{3}{|c|}{2.39} & 3.38 \\
\hline $2.50 \%$ & \multicolumn{3}{|c|}{2.7} & 3.73 \\
\hline $1 \%$ & \multicolumn{3}{|c|}{3.06} & 4.15 \\
\hline Variable & Coefficient & Std. Error & t-Statistic & Prob. \\
\hline ECT $(-1)$ & -0.3685 & 0.0621 & -5.9321 & 0.0000 \\
\hline \multicolumn{5}{|c|}{ Long-Run Coefficients } \\
\hline LFD & 0.2799 & 0.1238 & 2.2605 & 0.0298 \\
\hline LFPI & 1.1445 & 0.8359 & 1.3692 & 0.1792 \\
\hline LGDPPC & 1.3193 & 0.5841 & 2.2586 & 0.0299 \\
\hline LINV & -0.9094 & 0.5802 & -1.5674 & 0.1255 \\
\hline LURB & -1.1365 & 0.5072 & -2.2408 & 0.0311 \\
\hline $\mathrm{C}$ & 23.8058 & 10.2562 & 2.3211 & 0.0259 \\
\hline
\end{tabular}

Short-Run Estimates 


\begin{tabular}{lllll} 
& Test Statistic & Value & df & Prob. \\
LFD & F-statistic & 23.8124 & $(2,37)$ & 0.0000 \\
LFDI & F-statistic & 6.6181 & $(2,37)$ & 0.0035 \\
LGDPPC & F-statistic & 7.9245 & $(2,37)$ & 0.0014 \\
LINV & F-statistic & 5.0021 & $(1,37)$ & 0.0314 \\
LURB & F-statistic & 196.8092 & $(3,37)$ & 0.0000 \\
\hline
\end{tabular}

\subsection{Granger-Causality}

Due to the inability of the ARDL model to estimate the direction of causality, the study employs the Granger-causality based on VAR to examine the direction of causality among the variables. Table 4 shows that the null hypothesis that LFD does not Granger Cause LCO2, LFPI does not Granger Cause $\mathrm{LCO}_{2}$, LGDPPC does not Granger Cause $\mathrm{LCO}_{2}$, LINV does not Granger Cause $\mathrm{LCO}_{2}$, LURB does not Granger Cause $\mathrm{LCO}_{2}$, LFPI does not Granger Cause LGDPPC, LINV does not Granger Cause LGDPPC and LURB does not Granger Cause LGDPPC is rejected at $5 \%$ significance level. In other words, a unidirectional causality exists running from LFD $\rightarrow$ $\mathrm{LCO}_{2}, \mathrm{LFPI} \rightarrow \mathrm{LCO}_{2}, \mathrm{LGDPPC} \rightarrow \mathrm{LCO}_{2}, \mathrm{LINV} \rightarrow \mathrm{LCO}_{2}, \mathrm{LURB} \rightarrow \mathrm{LCO}_{2}, \mathrm{LFPI} \rightarrow$ LGDPPC, LINV $\rightarrow$ LGDPPC and LURB $\rightarrow$ LGDPPC.

Table 4. Granger-Causality Test

\begin{tabular}{|c|c|c|c|}
\hline Null Hypothesis: & Obs & F-Statistic & Prob. \\
\hline LFD does not Granger Cause $\mathrm{LCO}_{2}$ & 49 & 4.0666 & $0.0240^{*}$ \\
\hline $\mathrm{LCO}_{2}$ does not Granger Cause LFD & & 0.6512 & 0.5264 \\
\hline LFPI does not Granger Cause $\mathrm{LCO}_{2}$ & 49 & 6.3708 & $0.0037 *$ \\
\hline $\mathrm{LCO}_{2}$ does not Granger Cause LFPI & & 0.4272 & 0.6550 \\
\hline LGDPPC does not Granger Cause $\mathrm{LCO}_{2}$ & 49 & 3.2004 & $0.0504 *$ \\
\hline $\mathrm{LCO}_{2}$ does not Granger Cause LGDPPC & & 0.0393 & 0.9615 \\
\hline LINV does not Granger Cause $\mathrm{LCO}_{2}$ & 49 & 3.2650 & $0.0476^{*}$ \\
\hline $\mathrm{LCO}_{2}$ does not Granger Cause LINV & & 0.8357 & 0.4403 \\
\hline LURB does not Granger Cause LCO2 & 49 & 7.1208 & $0.0021^{*}$ \\
\hline $\mathrm{LCO}_{2}$ does not Granger Cause LURB & & 0.1288 & 0.8795 \\
\hline LFPI does not Granger Cause LFD & 49 & 2.3579 & 0.1065 \\
\hline LFD does not Granger Cause LFPI & & 1.6267 & 0.2082 \\
\hline LGDPPC does not Granger Cause LFD & 49 & 1.7796 & 0.1806 \\
\hline
\end{tabular}


LFD does not Granger Cause LGDPPC

\begin{tabular}{lll} 
& 1.9466 & 0.1549 \\
49 & 2.8386 & 0.0693 \\
& 1.5907 & 0.2153 \\
49 & 2.2687 & 0.1154 \\
& 1.5732 & 0.2188 \\
49 & 1.0746 & 0.3502 \\
& 4.1597 & $0.0221^{*}$ \\
49 & 2.1020 & 0.1343 \\
& 2.7031 & 0.0781 \\
49 & 2.1663 & 0.1267 \\
& 1.0893 & 0.3454 \\
49 & 3.5537 & $0.0371^{*}$ \\
& 0.9156 & 0.4078 \\
49 & 3.8929 & $0.0278^{*}$ \\
& 0.7085 & 0.4979 \\
49 & 2.2773 & 0.1145 \\
& 1.2396 & 0.2994 \\
\hline
\end{tabular}

LINV does not Granger Cause LFD

LFD does not Granger Cause LINV

LURB does not Granger Cause LFD

LFD does not Granger Cause LURB

LGDPPC does not Granger Cause LFPI

LFPI does not Granger Cause LGDPPC

LINV does not Granger Cause LFPI

LFPI does not Granger Cause LINV

LURB does not Granger Cause LFPI

LFPI does not Granger Cause LURB

LINV does not Granger Cause LGDPPC

LGDPPC does not Granger Cause LINV

LURB does not Granger Cause LGDPPC

LGDPPC does not Granger Cause LURB

LURB does not Granger Cause LINV

LINV does not Granger Cause LURB

*Rejection of the null hypothesis at 5\% significance level

\subsection{Innovation Accounting}

The ARDL method is able to examine the long-run and short-run equilibrium relationship while the Granger-causality test examines the direction of causality. Nevertheless, the impulseresponse function that traces the effect of a shock from one endogenous variable on the other variables is uncertain in both ARDL and Granger-causality. Against the backdrop, the study employs the innovation accounting based on Cholesky's technique in order to analyze the variance decomposition of each random innovation affecting the variables in the VAR.

Table 5 shows that $20 \%$ of future shocks in $\mathrm{LCO}_{2}$ are due to fluctuations in $\mathrm{LFD}, 12 \%$ of future shocks in $\mathrm{LCO}_{2}$ are due to fluctuations in LURB, $12 \%$ of future shocks in $\mathrm{LCO}_{2}$ are due to fluctuations in LGDPPC, $12 \%$ of future shocks in $\mathrm{LCO}_{2}$ are due to fluctuations in LFPI and $10 \%$ of future shocks in $\mathrm{LCO}_{2}$ are due to fluctuations in LINV.

Table 5 shows that $9 \%$ of future shocks in LFD are due to fluctuations in LURB, $7 \%$ of future shocks in LFD are due to fluctuations in LFPI, $5 \%$ of future shocks in LFD are due to 
fluctuations in $\mathrm{LCO}_{2}, 4 \%$ of future shocks in LFD are due to fluctuations in LINV and 3\% of future shocks in LFD are due to fluctuations in LGDPPC.

Table 5 shows that $22 \%$ of future shocks in LFPI are due to fluctuations in $\mathrm{LCO}_{2}, 17 \%$ of future shocks in LFPI are due to fluctuations in LINV, $4 \%$ of future shocks in LFPI are due to fluctuations in LFD, 3\% of future shocks in LFPI are due to fluctuations in LGDPPC and 3\% of future shocks in LFPI are due to fluctuations in LURB.

Moreover, evidence from Table 5 shows that $16 \%$ of future shocks in LGDPPC are due to fluctuations in LFD, $15 \%$ of future shocks in LGDPPC are due to fluctuations in LFPI, $6 \%$ of future shocks in LGDPPC are due to fluctuations in $\mathrm{LCO}_{2}, 6 \%$ of future shocks in LGDPPC are due to fluctuations in LURB and 3\% of future shocks in LGDPPC are due to fluctuations in LINV.

Table 5 shows that $43 \%$ of future shocks in LINV are due to fluctuations in LGDPPC, $22 \%$ of future shocks in LINV are due to fluctuations in LFPI, 13\% of future shocks in LINV are due to fluctuations in LFD, $8 \%$ of future shocks in LINV are due to fluctuations in $\mathrm{LCO}_{2}$, and $7 \%$ of future shocks in LINV are due to fluctuations in LURB.

Table 5 shows that $22 \%$ of future shocks in LURB are due to fluctuations in LFPI, $17 \%$ of future shocks in LURB are due to fluctuations in LFD, 11\% of future shocks in LURB are due to fluctuations in $\mathrm{LCO}_{2}, 4 \%$ of future shocks in LURB are due to fluctuations in LINV and 3\% of future shocks in LURB are due to fluctuations in LGDPPC.

Table 5. Innovation Accounting based on Cholesky's technique

\begin{tabular}{llllllll}
\hline \multicolumn{7}{c}{ Cholesky Ordering: LCO2 LFD LFPI LGDPPC LINV LURB } \\
\hline \multirow{8}{*}{ Period } & S.E. & LCO $_{2}$ & LFD & LFPI & LGDPPC & LINV & LURB \\
1 & 0.0993 & 100 & 0 & 0 & 0 & 0 & 0 \\
2 & 0.1269 & 79.7608 & 1.4338 & 6.4066 & 1.7759 & 6.9513 & 3.6717 \\
3 & 0.1418 & 66.0882 & 4.6148 & 5.8308 & 7.2927 & 7.1410 & 9.0324 \\
4 & 0.1539 & 56.2366 & 9.1601 & 5.1358 & 11.5908 & 6.1644 & 11.7123
\end{tabular}




$\begin{array}{llllllll}5 & 0.1648 & 49.0876 & 13.8754 & 5.5366 & 12.6515 & 6.3847 & 12.4643 \\ 6 & 0.1751 & 43.5824 & 17.2190 & 7.1549 & 12.3862 & 7.0601 & 12.5974 \\ 7 & 0.1844 & 39.7180 & 18.9764 & 8.7894 & 12.0108 & 7.8950 & 12.6103 \\ 8 & 0.1923 & 37.2444 & 19.7227 & 9.9723 & 11.8212 & 8.7004 & 12.5389 \\ 9 & 0.1986 & 35.7097 & 19.9575 & 10.8655 & 11.7997 & 9.2882 & 12.3795 \\ 10 & 0.2035 & 34.7564 & 19.9377 & 11.6039 & 11.9070 & 9.6165 & 12.1785\end{array}$

Variance Decomposition of LFD:

$\begin{array}{llllllll}\text { Period } & \text { S.E. } & \mathrm{LCO}_{2} & \text { LFD } & \text { LFPI } & \text { LGDPPC } & \text { LINV } & \text { LURB } \\ 1 & 0.2169 & 2.8661 & 97.1339 & 0 & 0 & 0 & 0 \\ 2 & 0.2858 & 1.7426 & 93.8924 & 0.0073 & 0.2592 & 3.1604 & 0.9382 \\ 3 & 0.3219 & 1.9174 & 90.2623 & 0.1890 & 0.3001 & 5.1323 & 2.1988 \\ 4 & 0.3433 & 2.4485 & 87.1642 & 1.2769 & 0.3184 & 5.1899 & 3.6021 \\ 5 & 0.3584 & 3.1038 & 83.9272 & 2.5853 & 0.4743 & 4.8416 & 5.0677 \\ 6 & 0.3700 & 3.7001 & 80.8845 & 3.5903 & 0.9000 & 4.5503 & 6.3748 \\ 7 & 0.3794 & 4.1253 & 78.2185 & 4.4068 & 1.5225 & 4.3289 & 7.3980 \\ 8 & 0.3877 & 4.4091 & 75.8622 & 5.2001 & 2.1989 & 4.1536 & 8.1761 \\ 9 & 0.3954 & 4.6258 & 73.6977 & 6.0043 & 2.8580 & 4.0195 & 8.7948 \\ 10 & 0.4028 & 4.8282 & 71.6546 & 6.7935 & 3.4754 & 3.9358 & 9.3125\end{array}$

\begin{tabular}{|c|c|c|c|c|c|c|c|}
\hline Period & S.E. & $\mathrm{LCO}_{2}$ & LFD & LFPI & LGDPPC & LINV & LURB \\
\hline 1 & 0.0504 & 12.7232 & 1.9408 & 85.3360 & 0 & 0 & 0 \\
\hline & 0.0603 & 15.1654 & 4.6623 & 73.9175 & 0.3397 & 5.2729 & 0.6423 \\
\hline & 0.0679 & 17.9235 & 5.4093 & 61.9620 & 1.4613 & 12.0699 & .1739 \\
\hline & 0.0727 & 19.2927 & 5.1299 & 56.3978 & 1.8458 & 15.9650 & 1.3689 \\
\hline & 0.0757 & 20.2140 & 4.7770 & 54.2947 & 1.9300 & 17.2673 & 1.517 \\
\hline & 0.0779 & 20.9908 & 4.5240 & 53.2360 & 2.0288 & 17.4938 & 1.7267 \\
\hline & 0.0794 & 21.6207 & 4.3488 & 52.4400 & 2.2243 & 17.3821 & 1.984 \\
\hline & 0.0806 & 22.0382 & 4.2256 & 51.8394 & 2.4881 & 17.1571 & 2.2515 \\
\hline & 0.0815 & 22.2623 & 4.1403 & 51.4051 & 2.7766 & 16.8918 & 2.523 \\
\hline 0 & 0.0824 & 22.3507 & 4.0859 & 51.0547 & 3.0742 & 16.6195 & 2.815 \\
\hline \multicolumn{8}{|c|}{ Variance Decomposition of LGDPPC: } \\
\hline Period & S.E. & $\mathrm{LCO}_{2}$ & LFD & LFPI & LGDPPC & LINV & LURB \\
\hline 1 & 0.0614 & 14.1719 & 16.2512 & 0.3096 & 69.2673 & 0 & 0 \\
\hline & 0.0896 & 10.6471 & 18.3542 & 1.2900 & 66.1941 & 2.9986 & 0.516 \\
\hline & 0.1107 & 7.3407 & 18.7102 & 3.0310 & 65.0289 & 4.6290 & 1.260 \\
\hline & 0.1263 & 5.6365 & 18.6419 & 4.4928 & 64.9566 & 4.3493 & 1.922 \\
\hline & 0.1386 & 4.7605 & 18.4578 & 6.2295 & 64.3740 & 3.6768 & 2.5013 \\
\hline & 0.1492 & 4.3729 & 18.1698 & 8.2555 & 62.9244 & 3.1998 & 3.077 \\
\hline & 0.1589 & 4.3595 & 17.7693 & 10.2890 & 60.8863 & 3.0058 & 3.6901 \\
\hline & 0.1680 & 4.6333 & 17.3037 & 12.1199 & 58.5865 & 3.0361 & 4.3205 \\
\hline & 0.1767 & 5.0890 & 16.8265 & 13.7103 & 56.2473 & 3.1907 & 4.9362 \\
\hline 10 & 0.1849 & 5.6324 & 16.3685 & 15.0879 & 54.0083 & 3.3837 & 5.519 \\
\hline \multicolumn{8}{|c|}{ Variance Decomposition of LINV: } \\
\hline Period & S.E. & $\mathrm{LCO}_{2}$ & LFD & LFPI & LGDPPC & LINV & LURE \\
\hline & 0.0889 & 4.6359 & 3.2100 & 0.9000 & 62.9882 & 28.2659 & 0 \\
\hline & & & & & & 20 & \\
\hline
\end{tabular}




\begin{tabular}{|c|c|c|c|c|c|c|c|}
\hline 3 & 0.1394 & 3.3592 & 12.2569 & 11.4412 & 56.0837 & 14.8820 & 1.9770 \\
\hline 4 & 0.1596 & 3.5428 & 13.7250 & 14.0148 & 53.4961 & 11.7461 & 3.4752 \\
\hline 5 & 0.1769 & 4.2468 & 14.2054 & 15.4809 & 51.4310 & 10.1394 & 4.4964 \\
\hline 6 & 0.1920 & 4.9494 & 14.2873 & 17.0316 & 49.3355 & 9.2131 & 5.1831 \\
\hline 7 & 0.2054 & 5.6325 & 14.1178 & 18.5772 & 47.3487 & 8.5825 & 5.7414 \\
\hline 8 & 0.2175 & 6.3104 & 13.8105 & 19.8489 & 45.6411 & 8.1363 & 6.2529 \\
\hline 9 & 0.2285 & 6.9516 & 13.4677 & 20.8348 & 44.2035 & 7.8166 & 6.7257 \\
\hline 10 & 0.2386 & 7.5271 & 13.1450 & 21.6358 & 42.9573 & 7.5738 & 7.1609 \\
\hline \multicolumn{8}{|c|}{ Variance Decomposition of LURB: } \\
\hline Period & S.E. & $\mathrm{LCO}_{2}$ & LFD & LFPI & LGDPPC & LINV & LURB \\
\hline 1 & 0.0056 & 12.2377 & 3.7533 & 7.6849 & 1.0828 & 3.7750 & 71.4663 \\
\hline 2 & 0.0112 & 11.9661 & 5.8353 & 10.5835 & 1.4188 & 3.2566 & 66.9397 \\
\hline 3 & 0.0171 & 11.0554 & 8.2430 & 13.0398 & 1.6510 & 2.0954 & 63.9154 \\
\hline 4 & 0.0231 & 10.3657 & 10.5453 & 15.2238 & 1.8386 & 1.1804 & 60.8462 \\
\hline 5 & 0.0292 & 10.0080 & 12.5437 & 16.9903 & 1.9962 & 0.8452 & 57.6165 \\
\hline 6 & 0.0355 & 9.9363 & 14.1670 & 18.3636 & 2.1341 & 1.0483 & 54.3507 \\
\hline 7 & 0.0419 & 10.0698 & 15.4169 & 19.4379 & 2.2641 & 1.5911 & 51.2202 \\
\hline 8 & 0.0483 & 10.3359 & 16.3324 & 20.3032 & 2.4012 & 2.2760 & 48.3514 \\
\hline 9 & 0.0545 & 10.6780 & 16.9686 & 21.0229 & 2.5592 & 2.9683 & 45.8030 \\
\hline 10 & 0.0604 & 11.0541 & 17.3836 & 21.6392 & 2.7474 & 3.5964 & 43.5793 \\
\hline
\end{tabular}

\subsection{Diagnostic and Stability Checks}

Diagnostic and stability checks were performed to examine the independence of the residuals. The Jarque-Bera test in Figure 3 shows that the null hypothesis of normal distribution in the residuals cannot be rejected at 5\% significance level. Table 6 shows the diagnostic tests of the ARDL model. The Breusch-Godfrey Serial Correlation Lagrange-multiplier test shows that, the null hypothesis of no serial correlation at lag order $\mathrm{h}$ cannot be rejected at $5 \%$ significance level. The Breusch-Pagan-Godfrey heteroskedasticity test shows that, the null hypothesis of constant variance cannot be rejected at 5\% significance level. The Ramsey RESET test shows that, the null hypothesis of no omitted variables in the model cannot be rejected at $5 \%$ significance level. 
Table 6. ARDL Diagnostic Test

\begin{tabular}{|c|c|c|c|}
\hline & Value & df & Prob. \\
\hline \multicolumn{4}{|c|}{ Breusch-Godfrey Serial Correlation LM Test: } \\
\hline F-statistic & 0.6832 & $(2,35)$ & 0.5116 \\
\hline \multicolumn{4}{|c|}{ Heteroskedasticity Test: Breusch-Pagan-Godfrey: } \\
\hline F-statistic & 0.4900 & $(11,37)$ & 0.8974 \\
\hline \multicolumn{4}{|c|}{ Ramsey RESET Test: } \\
\hline F-statistic & 0.0070 & $(1,36)$ & 0.9337 \\
\hline
\end{tabular}

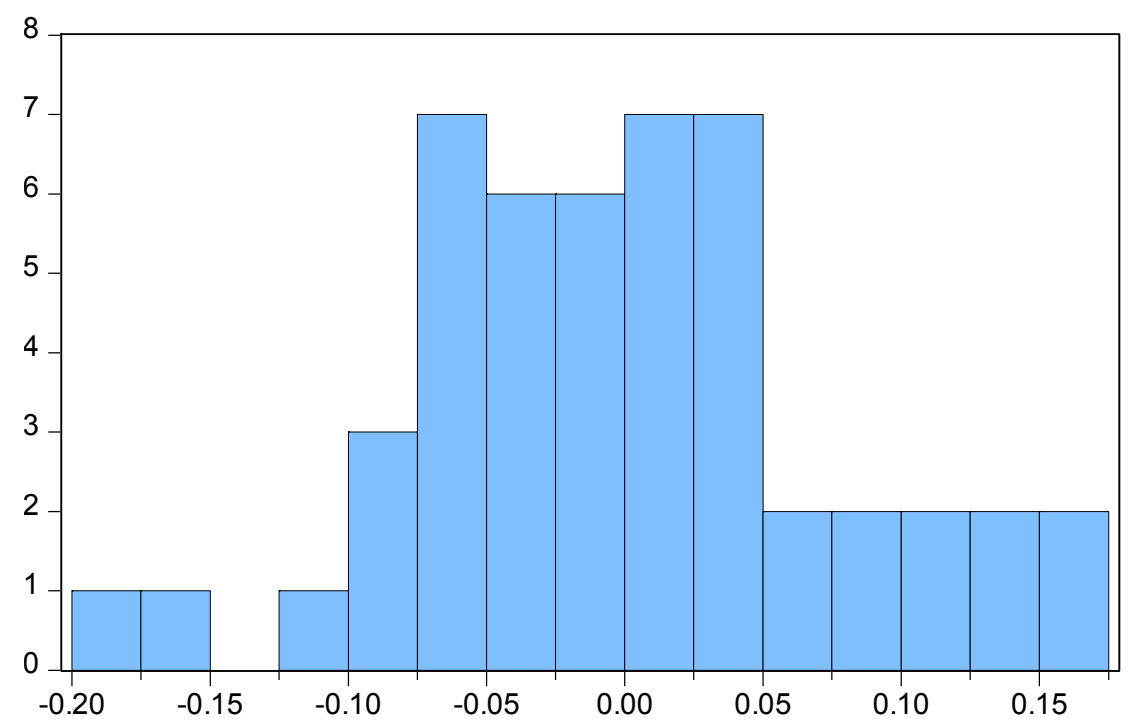

\begin{tabular}{|lc|}
\hline \multicolumn{2}{|l|}{ Series: Residuals } \\
Sample 1963 2011 \\
Observations & 49 \\
& \\
Mean & $2.21 \mathrm{e}-14$ \\
Median & -0.001684 \\
Maximum & 0.162221 \\
Minimum & -0.199935 \\
Std. Dev. & 0.077745 \\
Skewness & -0.019416 \\
Kurtosis & 3.131204 \\
& \\
Jarque-Bera & 0.038225 \\
Probability & 0.981069 \\
\hline
\end{tabular}

Figure 3. Jarque-Bera Test of Residuals

Figure 4 shows the CUSUM of Squares and CUSUM tests for checking the constancy of the cointegration space in the residuals of the ARDL model. Figure 4 shows that the CUSUM of Squares and CUSUM plots lie within the 5\% significance level. The diagnostic and stability checks shows that the residuals in the ARDL model are independent and have stable parameters to make unbiased statistical inferences. 

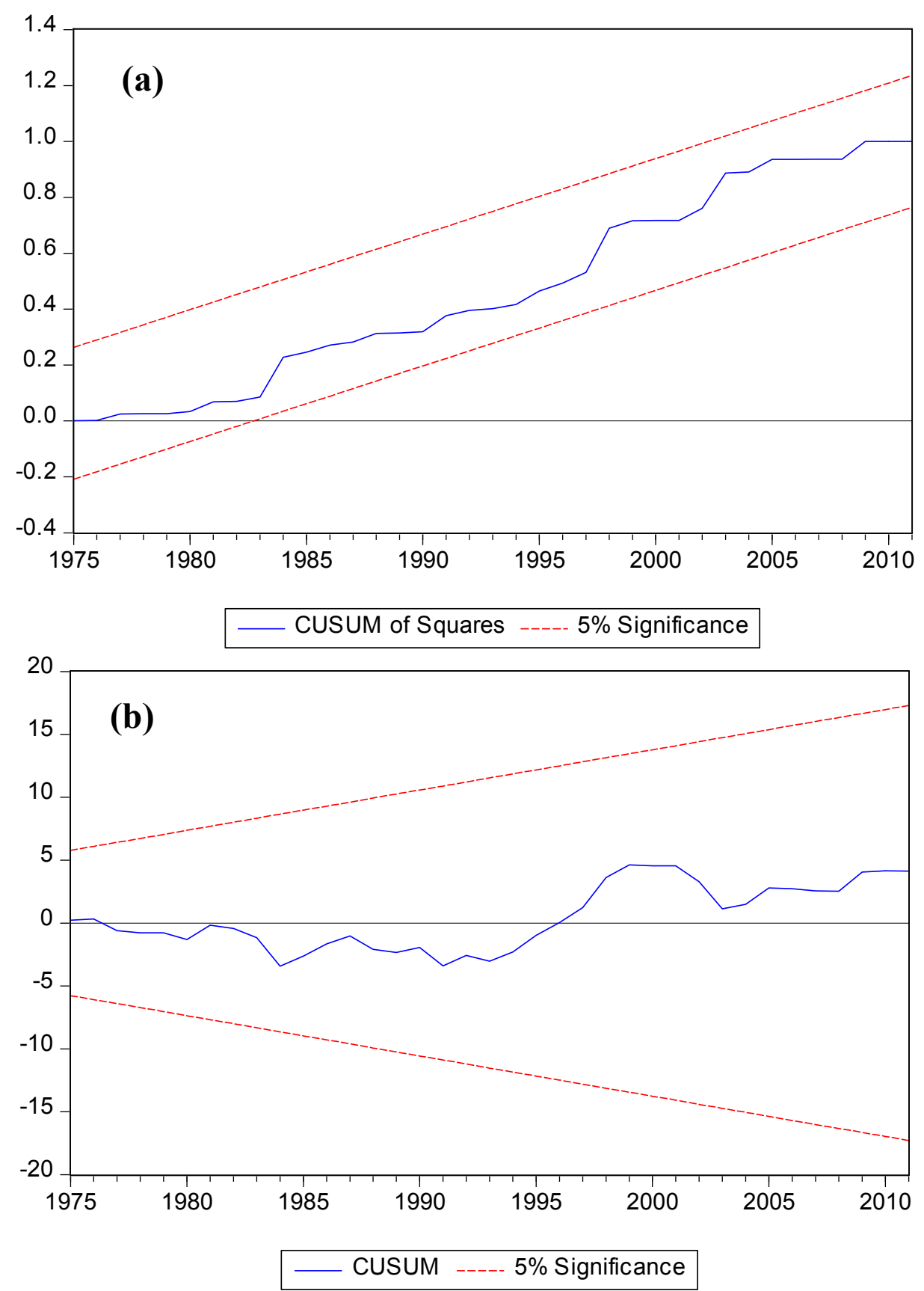

Figure 4. (a) CUSUM of Squares and (b) CUSUM of the Residuals 


\section{CONCLUSION AND POLICY RECOMMENDATIONS}

In this study, an attempt was made to investigate the Kenya case of a multivariate causality of carbon dioxide emissions by employing a time series data spanning from 1961-2011 using the ARDL method of cointegration analysis. The study further analyzed the direction of causality using the Granger-causality test and the variance decomposition based on Cholesky's technique in order to analyze each random innovation affecting the variables in the VAR.

The ARDL model shows a long-run and a short-run equilibrium relationship running from food production index, financial development, GDP per capita, industrialization and urbanization to carbon dioxide emissions. The long-run elasticities show that, a $1 \%$ increase in financial development increases carbon dioxide emissions by $0.28 \%$, a $1 \%$ increase in GDP per capita increases carbon dioxide emissions by $1.32 \%$ and a $1 \%$ increase in urbanization decreases carbon dioxide emissions by $1.14 \%$. The higher effect of per capita GDP and financial development on carbon dioxide emissions in Kenya is due to the higher depletion and degradation of natural resources for industrial purposes in order to achieve the 2030 development strategy of reaching a middle income country status of US $\$ 1,000$ per capita GDP with an accelerated economic growth of $6 \%$ [75]. As a global menace, Kenya is experiencing higher levels of urbanization in two industrial hubs namely Nairobi and Mombasa; the former been industrial and services hub for the local and regional markets while the later been a costal industrial hub for the emerging global markets. Nevertheless, Kenya is making the best out of urbanization to improve the labour force leading to an accelerated growth in economy and literacy which serves as a way of mitigating climate change and its impact through awareness creation.

Moreover, there was evidence of a unidirectional causality running from financial development to carbon dioxide emissions, food production index to carbon dioxide emissions, GDP per capita to carbon dioxide emissions, industrialization to carbon dioxide emissions, urbanization 
to carbon dioxide emissions, food production index to GDP per capita, industrialization to GDP per capita and urbanization to GDP per capita.

The innovation accounting based on the Cholesky's technique of variance decomposition shows that $20 \%$ of future shocks in carbon dioxide emissions are due to fluctuations in financial development. In addition, $9 \%$ of future shocks in financial development are due to fluctuations urbanization, $22 \%$ of future shocks in food production index are due to fluctuations in carbon dioxide emissions, $16 \%$ of future shocks in GDP per capita are due to fluctuations in financial development, $43 \%$ of future shocks in industrialization are due to fluctuations in GDP per capita and $22 \%$ of future shocks in urbanization are due to fluctuations in food production index.

The evidence from the long-run and short-run equilibrium relationship, the Granger-causality and the innovation accounting have policy implications for Kenya. All fast-growing developing economies are rapidly urbanizing, therefore Kenya should transform the rate of urbanization into good use through the creation of decent jobs and a strong labour force to increase economic productivity. Achieving higher levels of economic growth and productivity through technological improvements, innovation and creativity, diversification and high-value added to raw materials is a requirement for Kenya to achieve the middle-income status by 2030 .

Finally, as extreme levels of carbon dioxide emissions affect food production index, efforts by the Government of Kenya that promotes sustainable agriculture through modern technologies and improved agricultural techniques would boost Kenya's economic productivity, promote food security while mitigating climate change and its impacts. 


\section{REFERENCES}

1. Owusu P, Asumadu-Sarkodie S (2016) A Review of Renewable Energy Sources, Sustainability Issues and Climate Change Mitigation. Cogent Eng 3: 1167990.

2. Asumadu-Sarkodie S, Owusu P (2016) A Review of Ghana's Energy Sector National Energy Statistics and Policy Framework. Cogent Eng 3: 1155274.

3. Asumadu-Sarkodie S, Owusu PA (2016) The potential and economic viability of wind farms in Ghana. Energ Source Part A 38: 695-701.

4. Asumadu-Sarkodie S, Owusu PA (2016) The potential and economic viability of solar photovoltaic power in Ghana. Energ Source Part A 38: 709-716.

5. Owusu PA, Asumadu-Sarkodie S, Ameyo P (2016) A review of Ghana's water resource management and the future prospect. Cogent Eng 3: 1164275.

6. UNDP (2015) Linking Industralization with human development.

7. Asumadu-Sarkodie S, Owusu PA (2016) The relationship between carbon dioxide and agriculture in Ghana: a comparison of VECM and ARDL model. Environ Sci Pollut Res Int 23: 10968-10982.

8. UNDP (2015) Human Development Reports.

9. Asumadu-Sarkodie S, Owusu PA (2016) Feasibility of biomass heating system in Middle East Technical University, Northern Cyprus Campus. Cogent Eng 3: 1134304.

10. IMF (2015) Kenya: Financial status.

11. NEMA (2011) Kenya: State of the Environment and Outlook 2010.

12. Asumadu-Sarkodie S, Owusu PA (2016) Carbon dioxide emissions, GDP, energy use and population growth: a multivariate and causality analysis for Ghana, 1971-2013. Environ Sci Pollut Res Int 23: 13508-13520.

13. Asumadu-Sarkodie S, Owusu PA (2016) Multivariate co-integration analysis of the Kaya factors in Ghana. Environ Sci Pollut Res Int 23: 9934-9943.

14. Cerdeira Bento JP, Moutinho V (2016) CO2 emissions, non-renewable and renewable electricity production, economic growth, and international trade in Italy. Renew Sust Energ Rev 55: 142-155.

15. Seker F, Ertugrul HM, Cetin M (2015) The impact of foreign direct investment on environmental quality: A bounds testing and causality analysis for Turkey. Renew Sust Energ Rev 52: 347-356.

16. Apergis N, Ozturk I (2015) Testing Environmental Kuznets Curve hypothesis in Asian countries. Ecol Indic 52: 16-22.

17. Baek J (2015) A panel cointegration analysis of CO2 emissions, nuclear energy and income in major nuclear generating countries. Appl Energ 145: 133-138.

18. Narayan PK, Saboori B, Soleymani A (2016) Economic growth and carbon emissions. Econ Model 53: 388-397.

19. Acaravci A, Ozturk I (2010) On the relationship between energy consumption, CO 2 emissions and economic growth in Europe. Energy 35: 5412-5420.

20. Osabuohien ES, Efobi UR, Gitau CMW (2014) Beyond the Environmental Kuznets Curve in Africa: Evidence from Panel Cointegration. J Environ Pol 16: 517-538.

21. Tutulmaz O (2015) Environmental Kuznets Curve time series application for Turkey: Why controversial results exist for similar models? Renew Sust Energ Rev 50: 73-81.

22. Tiwari AK, Shahbaz M, Adnan Hye QM (2013) The environmental Kuznets curve and the role of coal consumption in India: Cointegration and causality analysis in an open economy. Renew Sust Energ Rev 18: 519-527. 
23. Ben Abdallah K, Belloumi M, De Wolf D (2013) Indicators for sustainable energy development: A multivariate cointegration and causality analysis from Tunisian road transport sector. Renew Sust Energ Rev 25: 34-43.

24. Shahbaz M, Lean HH, Shabbir MS (2012) Environmental Kuznets Curve hypothesis in Pakistan: Cointegration and Granger causality. Renew Sust Energ Rev 16: 2947-2953.

25. Balaguer J, Cantavella M (2016) Estimating the environmental Kuznets curve for Spain by considering fuel oil prices (1874-2011). Ecol Indic 60: 853-859.

26. Babu SS, Datta SK (2016) A Study of Co-variation and Convergence of Alternative Measures of Sustainability on the Basis of Panel Data. Soc Indic Res 125: 377-396.

27. Asici AA, Acar S (2016) Does income growth relocate ecological footprint? Ecol Indic 61: 707-714.

28. Ben Jebli M, Ben Youssef S, Ozturk I (2016) Testing environmental Kuznets curve hypothesis: The role of renewable and non-renewable energy consumption and trade in OECD countries. Ecol Indic 60: 824-831.

29. Bilgili F, Kocak E, Bulut U (2016) The dynamic impact of renewable energy consumption on $\mathrm{CO} 2$ emissions: A revisited Environmental Kuznets Curve approach. Renew Sust Energ Rev 54: 838-845.

30. Al-Mulali U, Solarin SA, Ozturk I (2016) Investigating the presence of the environmental Kuznets curve (EKC) hypothesis in Kenya: an autoregressive distributed lag (ARDL) approach. Nat Hazards 80: 1729-1747.

31. Fujii H, Managi S (2016) Economic development and multiple air pollutant emissions from the industrial sector. Environmental Science and Pollution Research 23: 28022812.

32. Kang YQ, Zhao T, Yang YY (2016) Environmental Kuznets curve for CO2 emissions in China: A spatial panel data approach. Ecol Indic 63: 231-239.

33. Asumadu-Sarkodie S, Owusu PA (2016) The Relationship between Carbon Dioxide Emissions, Electricity Production and Consumption in Ghana. Energ Source Part B.

34. Hao Y, Liu YM (2016) The influential factors of urban PM2.5 concentrations in China: a spatial econometric analysis. Journal of Cleaner Production 112: 1443-1453.

35. Javid M, Sharif F (2016) Environmental Kuznets curve and financial development in Pakistan. Renew Sust Energ Rev 54: 406-414.

36. Ozturk I, Al-Mulali U, Saboori B (2016) Investigating the environmental Kuznets curve hypothesis: the role of tourism and ecological footprint. Environmental Science and Pollution Research 23: 1916-1928.

37. Narayan PK, Narayan S (2010) Carbon dioxide emissions and economic growth: Panel data evidence from developing countries. Energy Policy 38: 661-666.

38. Charfeddine L, Khediri KB (2016) Financial development and environmental quality in UAE: Cointegration with structural breaks. Renew Sust Energ Rev 55: 1322-1335.

39. Al-Torkistani HM, Salisu MA, Maimany KA (2016) Modeling a sustainable Saudi Arabian economy: the real issues. Int J Sust Dev World 23: 186-193.

40. Liu YS, Yan B, Zhou Y (2016) Urbanization, economic growth, and carbon dioxide emissions in China: A panel cointegration and causality analysis. J Geogr Sci 26: 131152.

41. Ohler A, Fetters I (2014) The causal relationship between renewable electricity generation and GDP growth: A study of energy sources. Energ Econ 43: 125-139.

42. Azhar Khan M, Zahir Khan M, Zaman K, et al. (2014) Global estimates of energy consumption and greenhouse gas emissions. Renew Sust Energ Rev 29: 336-344.

43. Caraiani C, Lungu CI, Dascălu C (2015) Energy consumption and GDP causality: A three-step analysis for emerging European countries. Renew Sust Energ Rev 44: 198210. 
44. Fuinhas JA, Marques AC (2012) Energy consumption and economic growth nexus in Portugal, Italy, Greece, Spain and Turkey: An ARDL bounds test approach (19652009). Energ Econ 34: 511-517.

45. Chang C-C (2010) A multivariate causality test of carbon dioxide emissions, energy consumption and economic growth in China. Appl Energ 87: 3533-3537.

46. Chen S-T, Kuo H-I, Chen C-C (2007) The relationship between GDP and electricity consumption in 10 Asian countries. Energy Policy 35: 2611-2621.

47. Ozturk I, Acaravci A (2011) Electricity consumption and real GDP causality nexus: Evidence from ARDL bounds testing approach for 11 MENA countries. Appl Energ 88: 2885-2892.

48. Sadorsky P (2011) Trade and energy consumption in the Middle East. Energ Econ 33: 739-749.

49. Asumadu-Sarkodie S, Owusu PA (2016) Forecasting Nigeria's Energy-Use by 2030, an Econometric Approach. Energ Source Part B.

50. Pao H-T, Tsai C-M (2011) Multivariate Granger causality between CO2 emissions, energy consumption, FDI (foreign direct investment) and GDP (gross domestic product): Evidence from a panel of BRIC (Brazil, Russian Federation, India, and China) countries. Energy 36: 685-693.

51. Hatzigeorgiou E, Polatidis H, Haralambopoulos D (2011) CO2 emissions, GDP and energy intensity: A multivariate cointegration and causality analysis for Greece, 19772007. Appl Energ 88: 1377-1385.

52. Asumadu-Sarkodie S, Owusu PA (2016) Energy use, carbon dioxide emissions, GDP, industrialization, financial development, and population, a causal nexus in Sri Lanka: With a subsequent prediction of energy use using neural network. Energ Source Part B 11: 889-899.

53. Soytas U, Sari R (2009) Energy consumption, economic growth, and carbon emissions: Challenges faced by an EU candidate member. Ecol Econ 68: 1667-1675.

54. Huang B-N, Hwang MJ, Yang CW (2008) Causal relationship between energy consumption and GDP growth revisited: A dynamic panel data approach. Ecol Econ 67: 41-54.

55. Lozano S, Gutiérrez E (2008) Non-parametric frontier approach to modelling the relationships among population, GDP, energy consumption and $\mathrm{CO} 2$ emissions. Ecol Econ 66: 687-699.

56. Gul S, Zou X, Hassan CH, et al. (2015) Causal nexus between energy consumption and carbon dioxide emission for Malaysia using maximum entropy bootstrap approach. Environmental Science and Pollution Research: 1-13.

57. Jammazi R, Aloui C (2015) On the interplay between energy consumption, economic growth and $\mathrm{CO} 2$ emission nexus in the GCC countries: A comparative analysis through wavelet approaches. Renew Sust Energ Rev 51: 1737-1751.

58. Qureshi MI, Rasli AM, Zaman K (2016) Energy crisis, greenhouse gas emissions and sectoral growth reforms: repairing the fabricated mosaic. Journal of Cleaner Production 112: 3657-3666.

59. Asumadu-Sarkodie S, Owusu PA (2016) Recent Evidence of the Relationship between Carbon Dioxide Emissions, Energy use, GDP and Population in Ghana: A Linear Regression Approach. Energ Source Part B.

60. Mohiuddin O, Asumadu-Sarkodie S, Obaidullah M (2016) The Relationship between Carbon Dioxide Emissions, Energy Consumption, and GDP: a Recent Evidence from Pakistan. Cogent Eng 3: 1210491.

61. Zhang X-P, Cheng X-M (2009) Energy consumption, carbon emissions, and economic growth in China. Ecol Econ 68: 2706-2712. 
62. Shahbaz M, Jam FA, Bibi S, et al. (2016) Multivariate Granger Causality between Co2 Emissions, Energy Intensity and Economic Growth in Portugal: Evidence from Cointegration and Causality Analysis. Technol Econ Dev Eco 22: 47-74.

63. Asumadu-Sarkodie S, Owusu PA (2016) Carbon Dioxide Emission, Electricity Consumption, Industrialization and Economic Growth Nexus: The Beninese Case. Energ Source Part B.

64. Asumadu-Sarkodie S, Owusu PA (2016) The Causal Nexus between Energy Use, Carbon Dioxide Emissions and Macroeconomic Variables in Ghana. Energ Source Part $B$.

65. Asumadu-Sarkodie S, Owusu PA (2016) The Causal Effect of Carbon Dioxide Emissions, Electricity Consumption, Economic Growth and Industrialization in Sierra Leone. Energ Source Part B.

66. Asumadu-Sarkodie S, Owusu PA (2016) A Multivariate Analysis of Carbon Dioxide Emissions, Electricity Consumption, Economic Growth, Financial Development, Industrialization and Urbanization in Senegal. Energ Source Part B.

67. Saidi K, Hammami S (2016) Economic growth, energy consumption and carbone dioxide emissions: recent evidence from panel data analysis for 58 countries. Qual Quant 50: 361-383.

68. Ahmed K, Shahbaz M, Kyophilavong P (2016) Revisiting the emissions-energy-trade nexus: evidence from the newly industrializing countries. Environ Sci Pollut Res Int.

69. Asafu-Adjaye J (2000) The relationship between energy consumption, energy prices and economic growth: time series evidence from Asian developing countries. Energ Econ 22: 615-625.

70. Asumadu-Sarkodie S, Owusu P (2016) The Casual Nexus between Child Mortality Rate, Fertility Rate, GDP, Household Final Consumption Expenditure, and Food Production Index. Cogent Econ \& Fin 4: 1191985.

71. World Bank (2015) Data.

72. Pesaran MH, Shin Y, Smith RJ (2001) Bounds testing approaches to the analysis of level relationships. Journal of applied econometrics 16: 289-326.

73. Johansen S (1995) Likelihood-based inference in cointegrated vector autoregressive models. OUP Catalogue.

74. Brown RL, Durbin J, Evans JM (1975) Techniques for testing the constancy of regression relationships over time. Journal of the Royal Statistical Society Series B (Methodological): 149-192.

75. World Bank (2011) Kenya - Turning the tide in turbulent times making the most of Kenya's demographic change and rapid urbanization. Washington, DC: World Bank. 